\title{
EL POTENCIAL DE LOS ESTUDIOS RETÓRICOS EN LA INVESTIGACIÓN CONTABLE*
}

\author{
FABIÁN LEONARDO QUINCHE MARTÍN** \\ UNIVERSIDAD NACIONAL DE COLOMBIA
}

Recibido/ Received/ Recebido: 11/01/2012 - Aceptado/ Accepted/Aprovado: 30/05/2012

\begin{abstract}
Resumen
El presente escrito busca mostrar el papel que ha tenido y potencial que pueden tener los estudios sociales de la ciencia en la investigación contable internacional y nacional. Parte de la percepción de la contabilidad como práctica social constructora de realidades y, al mismo tiempo, legitimadora de órdenes sociales particulares. En especial se hace énfasis en el papel de los estudios retóricos y en la naturaleza retórica de la contabilidad. Se ve a la retórica como todos aquellos dispositivos discursivos que son utilizados por un emisor (individual o colectivo) dentro de expresiones textuales, orales o pictóricas a través de las cuales se busca persuadir a un público. A partir de esto se ven los informes contables (internos, externos, entre otros) como instrumentos retóricos por los cuales las organizaciones buscan persuadir a diversos 'usuarios' y al mismo tiempo construir su legitimidad. El potencial de la investigación retórica en contabilidad es amplio y de tal amplitud se da cuenta en el texto.

Palabras clave: filosofía de la ciencia, sociología de la ciencia, sociología del conocimiento científico, retórica, perspectivas críticas e interpretativas de la contabilidad, estudios retóricos de la contabilidad.
\end{abstract}

\section{THE POTENTIAL OF THE RHETORICAL STUDIES IN THE COUNTABLE INVESTIGATION}

\begin{abstract}
This paper shows the role of social studies of science in international and national accounting and their current and future potential. The perception of accounting as a social practice which builds reality while legitimating particular social orders. The paper makes special emphasis on rhetorical studies role and the rhetorical nature of accounting. Rhetoric is considered as those discursive means which are used by a transmitter (individual or group) within textual, oral or pictorial expressions through which a public will be persuaded. Thus, accounting reports are considered rhetorical instruments by which corporations seek to persuade various users while building their legitimacy. The potential of rhetorical research in accounting is wide; this wideness is evidenced in the paper.

Keywords: philosophy of science, sociology of science, sociology of scientific knowledge, rhetoric, critical and interpretive perspectives of accounting, rhetorical studies of accounting.
\end{abstract}

* El Presente escrito es producto de la investigación que el autor se encuentra realizando como Tesis para la Maestría en Estudios Sociales de la Ciencia; el presente documento se alimenta de las ponencias presentadas en el XIX Congreso Colombiano de Contadores Públicos (Armenia, Agosto de 2010) y en el VIII Simposio Nacional de Investigación Contable y Docencia (Cali, Noviembre de 2010).

** Contador Público, Universidad Nacional de Colombia, Magister (c) en Estudios Sociales de la Ciencia, Universidad Nacional de Colombia. Miembro del Grupo "Contabilidad, Organizaciones y Medio Ambiente", Universidad Nacional de Colombia. Docente Investigador, Universidad la Gran Colombia. Correo electrónico: falequimar@gmail.com. 


\title{
O POTENCIAL DOS ESTUDOS RETÓRICOS NA PESQUISA CONTÁBIL
}

\begin{abstract}
Resumo
O presente escrito procura mostrar o papel que teve e a potencialidade que podem ter os estudos sociais da ciência na pesquisa contábil internacional e nacional. O texto parte da percepção da contabilidade como prática social construtora de realidades e ao mesmo tempo legitimadora de ordens sociais particulares. Enfatiza-se de maneira especial o papel dos estudos retóricos e da natureza retórica da contabilidade. Vê-se à retórica como todos aqueles dispositivos discursivos que são utilizados por um emissor (individual ou coletivo) dentro de expressões textuais, orais ou pictóricas através das quais se procura persuadir a um público. A partir disto os relatórios contábeis (internos, externos, entre outros) são vistos como instrumentos retóricos pelos quais as organizações procuram persuadir a diversos 'usuários' e ao mesmo tempo construir sua legitimidade. O potencial da pesquisa retórica em contabilidade é amplo e tal amplitude é demonstrada no texto.

Palavras chave: filosofia da ciência, sociologia da ciência, sociologia do conhecimento científico, retórica, perspectivas críticas da contabilidade, estudos retóricos em contabilidade.

Quinche, F. (2012) El potencial de los estudios retóricos en la investigación contable. En: Revista de la Facultad de Ciencias Económicas de la Universidad Militar Nueva Granada. rev.fac.cienc.econ, XX (1)
\end{abstract}

JEL: M40, M41, M49.

\section{Introducción}

Durante la última década la investigación contable en Colombia ha experimentado la búsqueda de diversas perspectivas y metodologías de investigación. Dentro de esta búsqueda ha sido importante el diferenciar la existencia de múltiples corrientes de investigación a nivel internacional (Chua, 1986; Hopper \& Powell, 1985; Hopwood \& Miller, 1994; Larrinaga, 1999; Ryan, Scapens, \& Theobald, 2004). Desde el ámbito nacional varios autores se han aproximado a tales diferenciaciones, tales como: Gómez (2004), Quinche (2006; 2008), Álvarez (2007), Rueda (2007), Arévalo \& Quinche (2008), Giraldo (2008), entre otros. Las perspectivas que se llegan a diferenciar incluyen: Corriente Principal, Corriente Interpretativa, Corriente de Relaciones de Poder y Corriente Crítica.

En particular las corrientes interpretativa, de poder y crítica tienen en común una crítica a la visión esencialista (luego explicada) de la investigación contable desde la corriente principal. Tal crítica parte igualmente de una mirada diferente acerca de la ciencia y la investigación científica. Sin querer desconocer otras fuentes, se puede argumentar que buena parte de estas perspectivas, alternativas a la corriente principal, beben de diversos autores de los Estudios Sociales de la Ciencia y la Tecnología (en adelante ESCT). Como se mostrará en el cuerpo del artículo los ESCT se separan de las visiones clásicas de la ciencia provenientes de la filosofía, la sociología o la historia (Popper, Lakatos, Merton, etc.); adoptan, como principios evaluadores de la ciencia y la tecnología, la simetría, la causalidad, la imparcialidad y la reflexividad, siendo estos principios enfatizados unos más que otros dependiendo de la escuela de ESCT que se trate; sus fuentes teóricas provienen de diversos campos de la filosofía (postestructuralista y postmoderna, principalmente), la antropología, la sociología, la economía y la historia; el proceso de construcción del conocimiento científico y de las tecnologías es su objeto de investigación, más allá de la institución científica; del mismo modo es el discurso científico el que se evalúa dentro del contexto en el que emerge.

Una de las perspectivas de los ESCT que ha tenido fuertes repercusiones en la investigación sobre la 
ciencia y la tecnología, así como sobre la vida social en general, es la dedicada a los Análisis del Discurso, y en particular la que intenta mostrar el carácter retórico de la ciencia. Lejos de ver el discurso científico como algo objetivo, reflejo de la realidad y ajeno a intereses particulares, el análisis retórico lo ve y lo analiza como un discurso emitido con objetivos específicos, uno de los cuales es la búsqueda de aceptación del nuevo conocimiento por la comunidad científica; su aparente objetividad y neutralidad, son dispositivos estilísticos que ayudan en el logro de dicho objetivo.

Si vemos a la contabilidad como una disciplina productora de conocimiento (científico o tecnológico) podemos decir que es posible evaluarla a través de los ojos de los ESCT. Durante varias décadas se ha intentado argumentar y dotar a la contabilidad de un estatuto científico. Los intentos por hacerlo se alimentan de las visiones de la filosofía de la ciencia. Así, se ha dicho que la contabilidad tiene todos los elementos que posee la ciencia: objeto, método, sujeto, teorías (Araujo, 2007; Ariza, 1996; Belkaoui, 1985; Cañibano, 1988; García, 2001; García, 1998; Lemos de la Cruz, 2006; Machado, 1994; 1999; Mattessich, 2002; Montesinos, 1999; Requena, 1977; Tascón, 1995; Tua, 1995), paradigmas, programas o tradiciones de investigación (Belkaoui, 1985; Cañibano, 1996; Lara, 1991; Martínez, 2006; Mattessich, 1995; Tua, 1990). Sin embargo, se puede decir también que la contabilidad es una disciplina construida socialmente y constructora de la realidad social. Esto nos lleva a plantear que evaluar la contabilidad implica tener en cuenta otros elementos más allá de lo 'puramente' científico: relaciones sociales, relaciones de poder, intereses, discursos, retórica, etc.; elementos que son tenidos en cuenta por los ESCT.

A partir de lo anterior, el presente escrito busca hacer una relación entre los ESCT y la contabilidad, evaluando las diversas relaciones que ha habido entre los dos campos de estudio. Del mismo modo, partiendo de la relación anterior, se busca hacer énfasis en el carácter retórico de la contabilidad a través de la mirada al análisis retórico, la retórica de la contabilidad y los potenciales de investigación retórica en contabilidad.
Así, el escrito se ordena de la siguiente manera: la siguiente sección tratará acerca de las miradas que la filosofía, la sociología, la historia, entre otras, han tenido acerca de la ciencia y su naturaleza; se recorrerán en particular las visiones esencialistas (provenientes de la filosofía moderna de la ciencia y la sociología de la ciencia de carácter mertoniano, dejando de lado otras) y visiones constructivistas que han surgido a partir de las críticas al esencialismo, concentrándome en las provenientes de los Estudios Sociales de la Ciencia y la Tecnología (ESCT). En la tercera sección, se profundiza el abordaje de una de tales visiones constructivistas, los estudios retóricos, o aquellos que buscan identificar los mecanismos por los cuales los 'expertos' buscan convencer o persuadir a un público especial o general. A partir de estas miradas, se recorren diversas expresiones del esencialismo y/o del constructivismo en la investigación contable en la cuarta sección. En quinto lugar, se amplía el espectro de investigaciones y posibilidades de investigación desde los estudios retóricos en la disciplina contable; para ello, se clasifican estas investigaciones en seis apartados: la retórica de la ciencia en contabilidad, la retórica de la normatividad y el proceso de normalización, la retórica en la educación contable, la retórica dentro de la práctica contable, la retórica de las teorías contables y la retórica de lo contable en otros campos disciplinares. Se cerrará con unas conclusiones.

\section{Entre esencialismo y constructivismo: las miradas filosóficas, históricas y socio- lógicas de la ciencia}

La presente sección busca hacer un barrido, muy superficial, claro está, de lo que han sido los (ESCT). Estos estudios provienen de diversas disciplinas: historia, sociología, filosofía, lingüística, ingenierías, entre muchas más. Las perspectivas son múltiples, pero voy a agruparlas en dos grandes categorías. El primero, lo llamaré, o le diré como le han llamado otros, una visión esencialista de la ciencia: la ciencia se concibe como algo puro, el producto más importante de nuestro conocimiento, no contaminado por 'factores' sociales, políticos, culturales, humanos en general. El segundo grupo, le vamos a llamar visión constructivista de la ciencia: la ciencia como práctica social, una de las dimensiones de la sociedad, deter- 
minada y determinante de las dimensiones culturales, políticas, contextuales en donde se produce, se construye el conocimiento científico.

\subsection{La ciencia como el producto más elevado del espíritu humano. Aproximaciones esen- cialistas a la 'naturaleza' de la ciencia}

Esta visión de la ciencia está inmersa incluso en la visión de los filósofos e historiadores de la ciencia, para los cuales la ciencia no tiene porqué ser justificada, simplemente es ciencia. Los filósofos de la ciencia se han encargado de delimitar, o demarcar, lo que es una buena ciencia, hablando de los resultados y la metodología de la ciencia, lo que la distingue de (y la hacen superior a) otras formas de conocimiento. Al mismo tiempo, han dejado en manos de los sociólogos el estudio de las formas de desviación de la institución científica. Una buena parte de la sociología de la ciencia ha asumido esta tarea. Una síntesis de esto se ve en la tabla 1.

Tabla 1. Síntesis de las aproximaciones esencialistas de la ciencia ${ }^{1}$

\begin{tabular}{|l|l|l|}
\hline \multicolumn{1}{|c|}{ Aproximación } & Autores & \multicolumn{1}{c|}{ Elementos clave } \\
\hline Verificacionismo & Woolgar (1991) & $\begin{array}{l}\text { Esta visión es considerada como inductivista en cuanto considera que es a partir de la observación o del conjunto } \\
\text { de observaciones que una generalización puede ser enunciada. El problema de esta visión es que cualquier afirma- } \\
\text { ción podría ser considerada como científica en cuanto pudiera ser confirmada por las observaciones, pero tendría } \\
\text { problemas cuando apareciera una observación que la contradijera }\end{array}$ \\
\hline Falsacionismo & Popper & $\begin{array}{l}\text { La ciencia después de Popper pierde el carácter de seguridad que tenía con el racionalismo y pasa a ser de } \\
\text { carácter hipotético, discutible. }\end{array}$ \\
\hline Deductivismo & $\begin{array}{l}\text { Se conforman dos tipos de hipótesis, aquellas que se encuentran en el núcleo o en el centro del programa, que } \\
\text { son incuestionables, incontrastables, y que son protegidas por las hipótesis auxiliares pertenecientes al cinturón } \\
\text { protector, estas últimas son las que afrontarán las diversas luchas de contrastación, verificación, comprobación, } \\
\text { etc. (Lakatos, 1989). }\end{array}$ \\
\hline $\begin{array}{l}\text { Sociología sistemáti- } \\
\text { ca de la ciencia }\end{array}$ & $\begin{array}{l}\text { El conocimiento producido por la ciencia y su funcionamiento interno, no era cuestionable. Lo que había que } \\
\text { explicar es el carácter sistémico de la ciencia como institución social. La ciencia se ve como un subsistema del } \\
\text { sistema social. De acuerdo con esto, lo que se debe estudiar son las normas con las que la ciencia es protegida. } \\
\text { La ciencia posee una 'estructura normativa' que la sociología de la ciencia debe estudiar. }\end{array}$ \\
\hline Merton & $\begin{array}{l}\text { La teoría de las revoluciones científicas de Kuhn considera que la ciencia tiene momentos de ruptura que están } \\
\text { ligados a la estabilidad o no de un paradigma y a la llegada de otro. } \\
\text { Los paradigmas contendrán, además, principios metafísicos muy generales que guían el trabajo dentro del para- } \\
\text { digma así como prescripciones metodológicas muy generales. La ciencia normal implica un grupo de problemas } \\
\text { no resueltos pero que no ponen en riesgo el paradigma en la medida en que se mantengan controlados. Este grupo } \\
\text { de problemas no resueltos se conoce como Anomalías }\end{array}$ \\
\hline $\begin{array}{l}\text { De revoluciones y pa- } \\
\text { radigmas }\end{array}$ & Kunnas \\
\hline
\end{tabular}

\subsection{De la ciencia y su impureza. Aproximaciones constructivistas a la ciencia}

Aquí es importante diferenciar entre la sociología de la ciencia y la sociología del conocimiento científico. Como he contado en la sección anterior, tanto la filosofía de la ciencia como la sociología de la ciencia consideran que el conocimiento es algo puro, aque- llo que nos acerca más al mundo de las ideas mientras nos aleja de los factores políticos. La ciencia, nos dicen no tiene nada de política, es neutral. La sociología del conocimiento científico, hace precisamente lo contrario. Se interesa por la ciencia como una práctica social constructora de conocimientos y de realidades. Lo que no quiere decir que se esté diciendo que lo que dice la ciencia sea mentira. Se

1 Imagen de la investigación. 
parte de una visión ontológica en la cual se considera que la realidad es construida por el ser humano, en tanto el ser humano es el que la denomina, el que le pone límites, el que la abstrae, con el objetivo, entre muchos más, de intervenir en ella, de sobrevivir. El ser humano, el colectivo de seres humanos, es el que define qué es un conocimiento aceptado y qué no, cómo elaborar tal conocimiento y cómo no. Y esto debido a que 'nunca' se podría llegar a conocer la 'verdadera' esencia y complejidad de la realidad.

Por otro lado, este proceso de definición de lo que es la realidad no está exento de controversias. De hecho, es en las controversias donde el conocimiento y la realidad se construyen. Esto es así por el ejercicio que los actores hacen del poder, ejercicio que emerge desde los enunciados, es transportado o traducido por los objetos y motiva la acción de los individuos. En la medida en que las redes sean mayores, el poder ejercido puede ser mayor y tener mayores efectos en la definición del conocimiento aceptado. Este conocimiento aceptado se estabiliza y llega a tener una duración amplia, lo que no significa que sea susceptible de ser transformado.

Así, los ESCT estarían en los límites de lo que en algún momento ya hemos nombrado como perspectivas interpretativas y perspectivas de relaciones de poder. Los límites son borrosos, como lo son los límites que diferencian unas disciplinas de otras, los que diferencian una teoría de otra, los que diferencian 'las esferas' de la sociedad, si algo así existe (ver tabla 2).

\section{Estudios de Retórica}

Los estudios de retórica en términos generales hacen parte de los análisis del discurso. Sin embargo, siendo un tipo particular de análisis del discurso, no es un tipo de análisis lejano de otras corrientes investigativas de los ESCT.

La percepción generalizada acerca de la retórica es la del discurso disfrazado, fraudulento, mentiroso. Para McCloskey (1994) esta percepción es producto de la vulgarización que acostumbran a realizar los diarios y de la que han sido víctimas palabras como 'anarquismo', 'sentimiento', 'moralidad', 'valores familiares' e incluso la 'ciencia' misma (lo que podría ser extrapolado a palabras como 'revolución', 'crítica', 'intervención', entre muchas más). La retórica es vista como un antónimo de la verdad.

La perspectiva que aquí se adoptará es la de la retórica en su versión más clásica, pero al mismo tiempo, más contemporánea. Aquella que considera a la retórica como el conjunto de herramientas discursivas que son utilizadas cotidianamente para llevar al otro al convencimiento en los enunciados. A continuación trataré de exponer algunas de las perspectivas que sobre la retórica se pueden encontrar.

\subsection{Perspectivas alrededor de los estudios retóricos}

Según Gill \& Whedbee $(2000,233)$ la retórica tiene múltiples significados "mientras que algunas [...] definiciones comparan la retórica con la persuasión, otras la caracterizan de manera más amplia, como tratándose de cualquier tipo de expresión instrumental. Una definición identifica la retórica con la argumentación; otra, con el lenguaje elocuente. Por último, mientras que algunas definiciones asocian la retórica exclusivamente con el discurso, al menos una de ellas deja abierta la posibilidad de que pueda incluir actividades y objetos no discursivos". Para Gill \& Whedbee (2000, 234), "la retórica es el discurso calculado para influir sobre un auditorio hacia cierto fin en particular. [...] Aunque las descripciones de los fines de la retórica discrepan bastante, el tema invariable es que se trata de un tipo de discurso instrumental. De un modo u otro, es un vehículo para reforzar, alterar o responder a las opiniones de un público determinado".

La crítica retórica tiene entre sus objetivos "determinar el modo por el cual la retórica invita a la construcción o reconstrucción de sucesos y fenómenos. Su método consiste en identificar las estructuras textuales, discutirlas y, en algunos casos, desarmarlas, a fin de establecer cómo operan para crear opiniones, sancionar ciertas maneras de mirar el mundo, o silenciar a determinadas personas o puntos de vista" (Gill \& Whedbee, 2000, 237).

Para Gill \& Whedbee (2000) la crítica retórica analiza los discursos a partir de tres preguntas básicas: ¿Qué 
Tabla 2. Síntesis de las aproximaciones constructivistas de la ciencia²

\begin{tabular}{|c|c|c|}
\hline & Aportes & Elementos importantes \\
\hline $\begin{array}{l}\text { Programa Fuerte de la So- } \\
\text { ciología del Conocimiento y } \\
\text { Social-Constructivismo }\end{array}$ & $\begin{array}{l}\text { David Bloor y Barry Barnes. A este grupo } \\
\text { se le conoce como el programa fuerte de } \\
\text { la sociología del conocimiento o la es- } \\
\text { cuela de Edimburgo. } \\
\text { Bloor (1998) principios para el estudio de } \\
\text { la ciencia } \\
\text { Collins (1997, 59) establece tres etapas } \\
\text { que se deben cumplir en el estudio de la } \\
\text { ciencia. } \\
\text { Programa empírico del relativismo } \\
\text { (EPOR) de Collins estudios de la cons- } \\
\text { trucción social de la tecnología (SCOT). } \\
\text { Estudios de la Construcción social de los } \\
\text { factos (hechos) y artefactos, o la perspec- } \\
\text { tiva social-constructivista de los ESCT. }\end{array}$ & $\begin{array}{l}\text { La asimetría con que son explicadas las diferentes formas de conocimiento: el co- } \\
\text { nocimiento científico, sobretodo aquél que ha sido aceptado, aprobado, valorado } \\
\text { como bueno, se debería explicar solamente por la filosofía, gracias a su veracidad; } \\
\text { por el contrario, el conocimiento tradicional, el conocimiento no científico y el } \\
\text { conocimiento que partiendo de la ciencia llega a ser considerado como errado } \\
\text { (como aquello de que la tierra es plana o que lo que llena el vacío es el éter), debe } \\
\text { ser explicado por razones sociológicas. }\end{array}$ \\
\hline $\begin{array}{l}\text { Estudios etnográficos y de } \\
\text { laboratorio }\end{array}$ & $\begin{array}{l}\text { Latour \& Woolgar (1995), Knorr-Cetina } \\
\text { (1994; 2005), Lynch, Livingstone \& Gar- } \\
\text { finkel (1994) }\end{array}$ & $\begin{array}{l}\text { Una importante tribu para estudiar debía ser la comunidad científica. } \\
\text { Esta observación implica la recolección de todo tipo de documentación: videos, } \\
\text { entrevistas, borradores, gráficos, listados, correspondencia, etc. con el fin de obte- } \\
\text { ner una imagen más adecuada acerca de lo que sucede en el laboratorio (Woolgar, } \\
\text { 1991). Se trata de hacerse uno de ellos sin llegar a convertirse por completo. Se } \\
\text { trata de hacerse un novato en medio de un grupo de expertos. }\end{array}$ \\
\hline $\begin{array}{l}\text { Estudios discursivos y retóri- } \\
\text { cos de la ciencia }\end{array}$ & $\begin{array}{l}\text { Gilbert \& Mulkay (1994); Latour (1992); } \\
\text { Potter (1998); Restrepo (2004); Woolgar } \\
\text { (1991); Ashmore, Myers, \& Potter (1994); } \\
\text { Lynch (1990). }\end{array}$ & $\begin{array}{l}\text { Como dice Woolgar "centraremos nuestra atención en la manera en que la ciencia } \\
\text { puede interpretarse como un discurso en el cual y a través del cual se consigue la } \\
\text { preexistencia de los objetos" (1991, 104). "Retórica es el nombre de la disciplina } \\
\text { que, durante milenios, ha estudiado cómo hacer que las personas crean algo o se } \\
\text { comporten de una determinada forma y que ha enseñado a la gente a persuadir a } \\
\text { los demás" (Latour, 1992, 30). Así, cuando se habla de retórica de la ciencia, en } \\
\text { primer lugar, se irá en contra de la tradición que plantea que la ciencia no utiliza la } \\
\text { retórica, sino que se basa en los hechos, y se planteará que los hechos y la forma } \\
\text { de argumentación que utilizan los científicos son el mayor ejemplo de la retórica } \\
\text { de la ciencia; en segundo lugar, se hablará de los diferentes mecanismos que } \\
\text { utilizan los científicos en sus publicaciones (artículos, libros, ponencias, videos, } \\
\text { documentales, tecnologías, etc.), como la voz pasiva, los gráficos, las tablas, la } \\
\text { estructura básica de los artículos (introducción, marco referencial, métodos, re- } \\
\text { sultados, conclusiones), la presentación de la experimentación en los textos, la } \\
\text { citación de fuentes, entre muchos más }\end{array}$ \\
\hline $\begin{array}{l}\text { La teoría del actor-red (TAR) } \\
\text { - que también ha sido llamada } \\
\text { 'sociología de la traducción', } \\
\text { 'sociología de las asociacio- } \\
\text { nes' }\end{array}$ & $\begin{array}{l}\text { Estudios de caso de controversias y pro- } \\
\text { cesos de construcción de conocimiento } \\
\text { y tecnología de tipo histórico (Callon, } \\
\text { 1986; Latour, 2001; Law, 1986); estudios } \\
\text { de observación participante en los espa- } \\
\text { cios de construcción del conocimiento y } \\
\text { la tecnología (Latour, 1994; 2001; Latour } \\
\text { \& Woolgar, 1995); y tiene análisis de dis- } \\
\text { cursos y retórica (Latour, 1991; 2001; Law } \\
\text { \& Akrich, 1994). }\end{array}$ & $\begin{array}{l}\text { Los estudiosos de la TAR consideran que hay una reducción de las causas de la } \\
\text { realidad a los 'factores sociales'. Estos se convierten en la fuente de explicación } \\
\text { de todo conocimiento, Io que expresa una falta de simetría en el estudio de la } \\
\text { construcción del conocimiento (Callon, 1980; 1986; 1989; Latour, 2008; Law, } \\
\text { 1986; Law \& Callon, 1994). Lo social, según estos autores, llega a ser visto por } \\
\text { las perspectivas constructivistas como el material que pega los elementos de la } \\
\text { realidad. Para ellos, Io social no debe ser visto como una sustancia, como un } \\
\text { pegamento, sino que debe ser visto como un movimiento. Lo social no es lo que } \\
\text { construye, como la metáfora de la construcción social indicaría, sino que es lo que } \\
\text { es construido. Lo social no explica, lo social debe ser explicado. } \\
\text { Latour (2008) Ilama la atención a la adjetivación que se ha hecho de lo social en } \\
\text { las diversas ciencias sociales }\end{array}$ \\
\hline
\end{tabular}

2 Imagen de la investigación. 
expectativas genera el contexto? ¿Qué es lo que el texto le presenta al público? y ¿Cuáles son los rasgos significativos del texto? A partir de estas preguntas, las autoras consideran que son varios los elementos que se pueden analizar desde la crítica retórica. Dentro de los elementos que responden a la pregunta inicial acerca de las expectativas que genera el contexto se encuentran: la exigencia (el problema o asunto a que se refiere el texto), la audiencia (las personas concretas a las que se dirige el orador), el género (la naturaleza misma del texto) y la credibilidad del orador (la posición social del orador en relación con el auditorio al que se dirige). Para responder a la pregunta acerca de lo que presenta el texto al público, Gill \& Whedbee enumeran: la persona retórica (la persona ficticia del autor creada en el texto), el auditorio implícito (o la audiencia ficticia simbolizada en el texto mismo), la percepción del contexto (la mención que se hace del contexto en el que opera el texto y/o la re-definición que el texto hace del contexto) y la ausencia (aquello que está ausente o que ha sido silenciado por el texto). Por último, para responder a la pregunta por las características del texto señalan: la estructura y temporalidad, la argumentación, la metáfora y la iconicidad.

Desde el énfasis en la interacción Jonathan Potter $(1998,52)$ define a la retórica como el "discurso utilizado para reforzar versiones particulares del mundo y para proteger estas versiones de la crítica". Potter (1998) considera que "la retórica no se debería limitar a expresiones manifiestamente argumentativas o explícitamente persuasivas y debería verse como un aspecto fundamental de la manera en que las personas interactúan y llevan a la comprensión". Así, las actitudes pueden llegar a ser vistas como posturas públicas inseparables de las controversias del momento. Posteriormente, Potter identifica dos tipos de retórica: una retórica ofensiva, encargada de socavar las descripciones alternativas, elaborada para reelaborar, dañar o reenmarcar una descripción; y una retórica defensiva, que resiste a la anterior y que protege las descripciones empleando diversas técnicas (Potter, 1998). El análisis retórico debe tener en cuenta qué tipo de retórica se está analizando con el fin de identificar los procedimientos a través de los cuales se construyen hechos o versiones factuales o se busca socavar dichas versiones. Potter denomina- rá a estas retóricas, en términos generales, discursos cosificadores y discursos ironizadores.

Bazerman (1988) define la retórica como "el más amplio estudio de cómo la gente usa el lenguaje y otros símbolos para lograr objetivos humanos y llevar a cabo actividades humanas (...) un estudio práctico que ofrece a la gente un mayor control sobre su actividad simbólica". Para él, "la persuasión está en el corazón de la ciencia, no en el margen irrespetable. Una retórica inteligente practicada dentro de una comunidad de investigación seria, reconocible y comprometida es un método serio de búsqueda de la verdad. La comunicación científica más seria no es la que deja de lado la persuasión, sino la que persuade de la manera más profunda, más irresistible, y por lo tanto arrasa con los argumentos más superficiales" (Bazerman, 1988, 321).

Según Bazerman et al. (2005) a partir de la década de los ochenta se origina un movimiento denominado Retórica de la Indagación (Rhetoric of Inquiry), encabezado por autores como John Nelson, John Campbell, Arjo Klamer, Allan Megill, Donald McCloskey, entre otros. La publicación más importante de este movimiento es la compilación The Rhetoric of Human Sciences (Nelson, Megill \& McCloskey, 1987b). Para Nelson et al. (1987a, 3) "la investigación usa argumentos, y los argumentos usan retórica. La 'retórica' no es el mero ornamento o la mera superchería. Es retórica en el antiguo sentido de discurso persuasivo. En materias desde la prueba matemática hasta la crítica literaria, los investigadores escriben retóricamente". Dentro de este grupo se encontraban historiadores, sociólogos, filósofos, economistas, matemáticos, entre otros. "La retórica de la investigación toma como punto de partida que toda investigación -desde la biología hasta la teología- es argumento. Ni los hechos de la historia ni las pruebas matemáticas hablan por si mismas" (Bazerman et al., 2005, 74).

Bazerman et al.(2005) también reconocen el papel en el fortalecimiento de los estudios retóricos de autores como Bruno Latour (1992) y Steve Woolgar (Latour \& Woolgar, 1995). Para Latour (1992, 30) "la retórica es una disciplina fascinante aunque despreciada, pero se hace aún más importante cuando 
los debates son tan exacerbados que se convierten en científicos y técnicos (...). Los textos científicos o técnicos no se escriben de forma distinta por diferentes razas de escritores. Cuando llegas a ellos no significa que hayas dejado la retórica por el reino más tranquilo de la razón pura. Significa que la retórica se ha vuelto lo suficientemente acalorada, o que es todavía tan activa, como para que se tengan que introducir muchos más recursos para mantener en pie los debates". Así, es en las controversias donde con mayor fuerza se verá el uso de la retórica, en especial para provocar cierres de las mismas. Pero que una controversia se cierre, no quiere decir, que deje de haber retórica, al contrario, la retórica es más fuerte para que el cierre se mantenga. De acuerdo con Latour \& Woolgar (1995), "las materias primas dentro del laboratorio son rápidamente transformadas en moneda simbólica por los científicos a través de las actividades rutinarias de etiquetado, codificación, y clasificación"3.

Un campo cercano a la contabilidad en el que ha habido un movimiento importante desde los análisis retóricos es el de la economía. Su principal representante, Donald McCloskey (hoy Deirdre McCloskey) ha hecho un análisis profundo de la retórica que usa la economía, especialmente la economía neoclásica. Para McCloskey (1994, 320), "la ciencia es escrita con intención, la intención de persuadir a otros científicos, tales como los científicos económicos". En un texto anterior (McCloskey, 1983) comenta que los economistas tienen dos actitudes ante los discursos: una actitud oficial por la cual los economistas se reconocen a sí mismos como científicos en el moderno sentido de la palabra; estos científicos reconocen como propios y adecuados los requerimientos del método científico (hipotético-deductivo). La segunda actitud de los economistas, de carácter implícito, tiene que ver con el trabajo real de investigación, en donde los economistas hacen uso de una fuerte retórica para elaborar sus argumentos. "Aún en las materias estrechamente más técnicas de la discusión científica, los economistas tienen un conjunto compartido de convicciones sobre lo que hace un argumento fuerte, pero un conjunto que aún no ha sido examinado, que pueden comunicar a los estudiantes sólo tácitamente, y que contiene muchos elementos embarazosos para la retórica oficial" (McCloskey, 1983, 494). Para McCloskey, la economía utiliza principalmente figuras como la metáfora que se muestra con claridad en la utilización de modelos (McCloskey, 1983; 1990; 1994). Incluso afirma que las principales metáforas de la economía provienen de la contabilidad (Klamer \& McCloskey, 1992; McCloskey, 1993).

\subsection{Metodología del análisis retórico}

La metodología del análisis retórico es muy amplia, como para ser tratada en su totalidad en este escrito. Sin embargo a continuación se hará énfasis en algunos de los términos y elementos más importantes en el análisis retórico.

Inicialmente es necesario nombrar los cinco elementos de la composición que desde la retórica clásica son reconocidos. El primero de ellos es la Inventio o invención (también hallazgo), por medio del cual el orador escoge, descubre, construye los argumentos por los cuales dará apoyo, demostrará, sus tesis. $\mathrm{Al}$ escoger aquellos argumentos a utilizar el orador realiza una Dispositio u ordenamiento, con el fin de presentar los argumentos de una manera coherente dentro del discurso. Al presentar el discurso el orador debe hacerlo de un modo claro, vívido, adecuado al público al que se dirige, acto que se denomina Elocutio. Por último se encuentran la memne (o memoria), necesaria para recordar los argumentos y la disposición de los mismos, y la actio (o pronunciación), que implica las estrategias propias para la entonación del discurso. Estos dos últimos elementos han perdido importancia en la medida en que el análisis actual se hace principalmente sobre los textos escritos.

Dentro de los elementos tradicionalmente utilizados en la retórica se encuentran los recursos estilísticos. Entre ellos encontramos el ethos, el pathos y el logos.

- Logos: este recurso estilístico es utilizado apelando a la 'razón', a la lógica del argumento.

3 Ver también Bazerman et al., 2005, 75. 
Se podría decir que es el recurso más utilizado por la ciencia. La utilización de un método de investigación, la búsqueda de causalidades, la presentación de los argumentos dentro de un artículo, la presentación de gráficas y cuadros explicativos, y sobretodo el estilo impersonal de escritura, son apelaciones a la razón, al conocimiento. Sin embargo, este no es el único de los recursos que se utilizan en la ciencia.

- Ethos: con este recurso se apela a la credibilidad del orador. Dentro de la retórica de la ciencia esta credibilidad se apoya en recursos como los argumentos de autoridad, la apelación a la objetividad de la ciencia, etc. Parte de la credibilidad del científico está en la capacidad de innovación, innovación que debe estar hecha de acuerdo con el método científico, lo que le entrega mayor credibilidad al científico. Gross (2006, 27) considera que por sí mismos "todos los artículos científicos (...) están en medio de una red de relaciones de autoridad: la publicación en un journal respetado; detrás de tal publicación, una serie de garantías dadas a los científicos conectadas con una institución de investigación bien respetada; dentro del texto, un conjunto de citaciones ilustrando el artículo como el último resultado de un programa de investigación vital y en marcha”.

- Pathos: este recurso estilístico apelará a los sentimientos del auditorio, del público. En momentos de controversias científicas los sentimientos, las emociones, se harán claramente presentes al argumentar en contra del otro o al defender la posición propia. Más prominentemente, la principal emoción presente en la ciencia es la falta de emociones. Como plantea Gross (2006, 28-29) "la objetividad de la prosa científica es una invención retórica cuidadosamente trabajada, una apelación no racional a la autoridad de la razón: los informes científicos son el producto de elecciones verbales diseñadas para capitalizar la atractividad de una empresa que implica un mito conveniente, un mito en el que, aparentemente, la razón a subyugado a las pasiones. Pero la negación disciplinada de la emoción en la ciencia es solo un atributo para nuestra inversión apasionada en sus métodos y objetivos".

- Estilo: Como ya se ha enunciado, el estilo de la ciencia busca ser impersonal. Además de esto, se ha buscado que el estilo de la ciencia sea breve y claro. Para Gross (2006) el estilo de la ciencia es paradójico, un oxímoron: por un lado se quiere que sea modesto, claro, sin muchos ornamentos, en términos estilísticos; sin embargo, por otro, se quiere que el discurso científico lo abarque todo, sea heroico y solucione todo tipo de problemas.

Empero, dentro del estilo de la ciencia, varias figuras o tropos son utilizados continuamente. Según McCloskey, (1994) cuatro son las principales figuras utilizadas en la ciencia. La primera de ellas es la metáfora, para algunos la figura más utilizada y la figura sine qua non de la ciencia. "La forma fundamental del entendimiento humano es un proceso metafórico; la mente comprende una idea desconocida sólo por comparación con o en términos de algo que ya conoce. De este modo, el lenguaje metafórico de un texto presenta una perspectiva particular de la realidad que estructura la comprensión de una idea en términos de algo que ya comprendió previamente. Desde este punto de vista la metáfora modela la experiencia humana" (Gill \& Whedbee, 2000: 255). Para McCloskey (1983; 1990; 1994) y Klamer \& McCloskey (1992) las metáforas hacen parte inherente de la ciencia, tanto que tratar de hablar científicamente sin metáfora alguna, sería una contradicción. "Quizá el pensamiento es metafórico. Quizá remover la metáfora es remover el pensamiento" (McCloskey, 1983, 503).

La segunda figura es la sinécdoque, mediante la cual se refiere a un todo a través de un elemento parte del todo: hacer rodar la pecosa (el balón), la industria (el sector industrial) creció al X\%, etc. Una tercera figura puede ser la metonímia o la iconicidad, mediante las cuales un término es utilizado como símbolo de representación del referente: la niña de sus ojos (su novia; su hija), se enfrentó a tres espadas, etc. En cuarto lugar, 
la figura de la ironía se vuelve importante en la retórica científica. La ironía es el uso de argumentos de otros con el fin de refutarlos. Para McCloskey, la ironía puede ser usada luego de años de preparación.

Para Gill \& Whedbee (2000), todo discurso responde a la pregunta ¿qué es lo que presenta al público? ellas argumentan que los principales elementos que son presentados por un discurso son: la persona retórica, el auditorio implícito, la percepción del contexto y las ausencias. Por persona retórica se entiende la manera en la que el orador o emisor del discurso se define a si mismo, que sería distinto al orador mismo (es decir, el orador es diferente de la representación que hace de sí mismo). McCloskey (1994) llama a este elemento el 'autor implicado', el cual tiene un punto de vista particular, que en el caso de la ciencia se trata de desaparecer al autor con el estilo impersonal de escritura (McCloskey, 1994).

Hablar del auditorio implícito es hablar de los mecanismos que utiliza el orador o emisor del discurso con el fin de presentar a su audiencia. Se trata de los mecanismos por los cuales el autor construye al otro, que es muy diferente de aquel que está leyendo u oyendo el discurso. "El 'auditorio implícito' es ficticio, porque se crea a partir del contexto y sólo existe dentro del mundo simbólico que este propone" (Gill \& Whedbee, 2000: 246).

Cuando nos referimos a la percepción del contexto hablamos de los dispositivos que son usados por un orador para presentar 'su' percepción acerca del contexto. En este tipo de argumentos o dispositivos, se construye a través de la argumentación, la lógica del entorno del discurso, otorgando nuevos valores, nuevos roles, nuevos significados a los elementos constitutivos del entorno.

En la medida en que todo discurso tiene como intención construir los límites de la realidad y lograr con ello la persuasión de otros, este proceso deja por fuera múltiples objetos, personas, etc., que no llegan a ser nombrados en el discurso explícitamente y que se convierten en inaceptables o insignificantes. Este elemento puede ser conocido como la construcción de la ausencia.

- Autoridades: aunque ya se ha hablado de este tema, valga este espacio para ampliarlo. La retórica de la ciencia acude continuamente a las autoridades, que pueden ser de diversa clase. La forma principal de acudir a las autoridades es la citación de lo que han dicho en sus obras. Esto se expresa a través de citas tomadas textualmente, la referenciación de textos y la puesta o no de la referencia en la bibliografía de los artículos. Sin embargo, la autoridad principal en la ciencia es la naturaleza misma, invocada gracias al estilo impersonal que poseen los artículos científicos. Las publicaciones científicas se encuentran escritas de tal manera que la observación, lejos de ser mostrada como parte de la percepción del científico y la discusión con sus colegas, se muestra como un proceso propio del fenómeno en el cual el autor no tiene alguna incidencia.

Por último, y sin querer agotar los elementos o categorías del análisis retórico, se puede hablar de la capacidad que tienen los textos de elaborar Relatos (o Historias). Los textos científicos generan relatos cuando a partir de la aplicación de un método científico a una realidad concreta, pueden llegar a solucionar, interpretar, cuestionar, un problema específico. Para Gill \& Whedbee "la preocupación por la estructura del texto en la forma de, por ejemplo, introducción, cuerpo y conclusión de un discurso es tan antigua como el mismo arte de la retórica. La preocupación contemporánea por la estructura de los textos está relacionada con la tesis de Saussure (1986) de que experimentamos el discurso en forma lineal. De este modo, la estructura de un texto se entrelaza con el tiempo" (2000: 251). De manera que como plantea McCloskey, esta interrelación estructura-tiempo genera relatos lineales (1990; 1994). Según Clower (1988: 87), "contrario a la opinión popular y a las pretensiones de algunos científicos, la cantidad de todo el conocimiento comúnmente visto como 'científico' está expresado en términos de histo- 
rias que difieren poco de las historias contadas por los escritores de novelas serias. La semblanza no es accidental".

Si bien en este acápite se han mostrado algunos de los principales elementos que están inmersos en el discurso retórico, no se trata solamente de tratar de hacer uso de ellos para mejorar nuestra elaboración argumentativa, sino hacer de ellos nuestras herramientas metodológicas para futuros análisis del discurso.

\section{Del Esencialismo al Constructivismo en la pregunta por la 'naturaleza' de la Contabilidad}

\subsection{Las visiones esencialistas de la investigación contable}

En la contabilidad, valga decir de una vez, han predominado las visiones esencialistas de la contabilidad. Si seguimos de nuevo la clasificación de las cuatro perspectivas en contabilidad (dominante, crítica radical, relaciones de poder e interpretativa), es en la perspectiva dominante donde el esencialismo se hace más presente. En primer lugar, porque se considera que una buena investigación debe llevar a la apropiación de las metodologías de las ciencias naturales, metodologías que llevan al verdadero descubrimiento de las regularidades de la realidad.

Por otro lado, en el estudio de la contabilidad y en las pretensiones por hacer de ella una ciencia, se ha acudido principalmente a la filosofía de la ciencia para demarcar, delimitar, lo que es la ciencia contable y lo que no. La contabilidad ha sido demarcada a través de la definición de su método de otras disciplinas como la economía, la administración, las finanzas, sin nombrar otras. Alejándola de elementos sociales, políticos, culturales, de manera que la contabilidad llega a ser vista como una ciencia de aplicación universal, homogénea, delimitada.

Entre las múltiples definiciones del método podemos encontrar la propuesta de Mattessich $(2002)^{4}$, adaptada por Cañibano (1988), del método contable compuesto por cuatro pasos: el principio de dualidad, como la estructura básica de la contabilidad, la medición y valoración, las diversas formas de representación y la agregación. Este método respondería a un conjunto de principios (supuestos básicos), abstraídos a través del uso de la lógica. Tanto los principios como los elementos del método representarían la estructura de la contabilidad y la plantean como una disciplina homogénea, no problemática y neutral.

De igual manera, en la evaluación de la historia 'científica' de la contabilidad, las versiones esencialistas también se han hecho presentes. Breves ejemplos podemos encontrar en la propuesta de paradigmas de Belkaoui (1985; ver las críticas que a esta propuesta hace Martínez, 2006), la propuesta de programas de investigación de Cañibano (1996), los subprogramas de investigación en la elaboración de principios contables de Tua (1995), o la propuesta de tradiciones de investigación de Mattessich (1995).

Estas visiones de la historia de la contabilidad, aunque expresan las diferentes controversias que hay en la contabilidad, tienen múltiples problemas si se analizan desde una mirada constructivista. En primer lugar, son versiones lineales de la historia en las cuales la contabilidad se encuentra en 'progreso' dirigiéndose hacia un estadio cada vez mejor de la contabilidad. En segunda instancia, abordan la contabilidad desde una mirada a priori, a partir de la cual, se identifican los elementos de las diversas perspectivas que llevan a delimitar a la contabilidad como una ciencia. Tercero, la contabilidad es aislada de otras disciplinas, como si la contabilidad fuera una disciplina que trabajara en solitario. Cuarto, debido a lo anterior, no se tienen en cuenta perspectivas de investigación que ven a la contabilidad de una manera diferente, dejando dentro de sus propuestas visiones que responden a los mismos preconceptos epistemológicos, ontológicos, metodológicos y axiológicos. En otras palabras, las perspectivas presentadas en estas propuestas son clasificables dentro de la perspectiva dominante de la contabilidad, lo que deja

4 Edición original de 1964. 
de lado puntos de vista críticos e interpretativos de la misma.

\subsection{Constructivismo y contabilidad}

Los vínculos de la investigación contable con perspectivas constructivistas es de (ahora) vieja data. Para nosotros puede resultar novedoso en cuanto esta tradición no ha sido desarrollada en nuestro país. Pero tengo que reconocer que los desarrollos internacionales en tales vínculos, son bastante amplios y requieren un buen abordaje, que por motivos de espacio, aquí no voy a poder realizar.

El estudio de la contabilidad desde las perspectivas de los ESCT tiene diversos vínculos, autores, temáticas, de las que podemos charlar brevemente.

Si hablamos de relaciones directas entre los miembros de los ESCT e investigadores contables, podemos hablar de Peter Miller y de Michael Power, ambos miembros de la London School of Economics. Desde los años ochenta, Peter Miller junto a autores como Ted O'leary o Nikolas Rose, ha trabajado, desde una perspectiva Foucaultiana, que es muy cercana a los ESCT, el papel de la contabilidad en el gobierno de la vida económica. De hecho, Miller, junto con Burchell y otros, hace una compilación evaluativa de la perspectiva de Foucault (The Foucault Effect). En su texto de 1987, Miller \& O'leary (1987) analizan el surgimiento de las metodologías de costeo estándar. Este surgimiento es asociado con los discursos emergentes en los niveles estatales acerca de la eficiencia y la productividad. El costeo estándar es visto como una práctica de cálculo representante del aparato de poder proveniente de los discursos gubernamentales. Sin embargo, la contabilidad o el costeo estándar no es una práctica aislada, junto a ella se encuentran campos de saber como la administración científica y la psicología industrial, entre otros, que permiten el control del individuo y la realización de los discursos institucionales.

En 1994, Miller \& O'leary, acercándose a una perspectiva de estudios de laboratorio en la cual se ve al laboratorio como una fábrica de conocimiento, analizan la planta fabril como un laboratorio. Ambos, laboratorio y fábrica, pueden ser vis- tos como complejos ensamblados de elementos de producción de conocimiento. En este texto, Miller y O'leary "tratan el ensamblado de relaciones y la multiplicidad de locaciones dentro de las cuales la fábrica fue problematizada y en la cual los objetivos para el rediseño emergieron" (Miller \& O'leary, 1994, 145), sin dar una prioridad a los aspectos sociales o técnicos del cambio. Uno de los resultados del estudio fue la observación de la construcción de nuevas formas de 'ciudadanía económica'.

Hopwood \& Miller (1994) llevaron a cabo una compilación de textos abreviados de artículos influyentes de las perspectivas críticas e interpretativas de la contabilidad. En la compilación se pueden encontrar textos acerca de la retórica del cálculo contable (Thompson, 1994), el origen del poder contable en las prácticas de escritura, evaluación y disciplinamiento (Hoskin \& Macve, 1994) o la consolidación de la auditoría como una racionalidad apropiada por el conjunto de la sociedad (Power, 1994b).

En los últimos años Miller ha venido trabajando en temas de percepción y gobierno del riesgo, gobierno de la vida económica a partir de los cálculos contables, relaciones estado-mercado-riesgo, entre otros (Miller \& Rose, 2008).

Por su parte, Michael Power ha tenido un contacto más directo con los ESCT. Dentro de sus textos inicialmente adoptaba metodologías provenientes de los estudios social-constructivistas de la ciencia y la tecnología (Power, 1995). En 1994, editó una compilación de textos titulada Accounting and Science, Natural Inquiry and Commercial Reason (Power, 1994a), prologado por Bruno Latour, y con textos de autores como Theodore M. Porter (acerca del poder de la cuantificación en la sociedad moderna), John Law y Madeleine Akrich (autores representativos de la TAR), Steve Fuller, entre otros autores de los ESCT, y de Peter Miller, Ted O'leary, Keith Robson, autores representativos de las perspectivas críticas e interpretativas de la contabilidad.

Desde la TAR, autores como Chua (Briers \& Chua, 2001; Chua \& Preston, 1994), Lowe (2000; 2001a; 2001b; 2004a; 2004b; Lowe \& Koh, 2007), Mou- 
ritsen (Dechow \& Mouritsen, 2005; Mouritsen, Hansen \& Hansen, 2009; Mouritsen \& Larsen, 2005; Mouritsen, Larsen \& Bukh, 2001b; Mouritsen, Larsen \& Hansen, 2002; Mouritsen \& Thrane, 2006), entre otros autores (Ahrens, Chwastiak, Colwyn, Gendron, Jaecle, etc.) han analizado problemáticas como el capital intelectual, la presupuestación hospitalaria, el riesgo, los sistemas de gestión, y muchos temas más, tratándolos, no desde una perspectiva tradicional, sino buscando rastrear los ensamblajes que llevan a que la sociedad sea construida.

\section{Los estudios retóricos en la investiga- ción contable. Avances y potenciales}

\subsection{El carácter Retórico de la Contabilidad}

Tal como ha pasado con la ciencia, se dice de la contabilidad que no posee retórica; que su discurso está libre de juicios, libre de decoraciones retóricas que eviten o promuevan acciones en los usuarios de la información que ella produce; que ella representa fielmente la realidad, sin tomar partido, apegándose a los hechos. Esto está lejos de ser cierto. La contabilidad, al igual que la ciencia y al igual que la mayoría de discursos expresados en la sociedad, es retórica. Es retórica por varias razones: es un discurso emitido por una comunidad, con un mensaje especial y dirigido a otros con el fin de influir sus decisiones. Con una pequeña revisión a los elementos retóricos presentes en la contabilidad se busca en esta sección argumentar esta proposición. Se ofrecerán diversos ejemplos, aunque no de todos los elementos comentados en la sección anterior.

De lo primero que tenemos que hablar entonces es de los diferentes Géneros en contabilidad. Se puede llegar a argumentar que los tres tipos de géneros discursivos (deliberativo, judicial, epidíctico) están presentes en la contabilidad, incluso, los tres géneros se presentan al mismo tiempo en los informes contables. Los informes contables son una forma de género deliberativo en cuanto son usados para analizar las opciones de acción futura en una organización, en particular, podemos ver que en campos como la evaluación de proyectos de inversión, los presupuestos, entre otros, es necesaria la evaluación de las posibles repercusiones de las decisiones actua- les con el fin de tomar las más 'adecuadas' al futuro de la organización. Por otro lado, el género judicial se encuentra presente en todas las formas de información contable en cuanto ella se refiere a hechos pasados que son evaluados en el presente y definen si lo llevado a cabo fue bueno o no. Por último el género epidíctico se encuentra presente en la valoración que se hace de las organizaciones en sus propios informes; los informes anuales, los informes de sostenibilidad y otros por el estilo, proveen una gran cantidad de juicios de valor acerca de las acciones positivas que hacen las empresas mismas.

Siguiendo el mismo orden de la sección anterior, es el turno de hablar de la construcción de los argumentos en contabilidad. Si nos detenemos a considerar el método contable, tal como los exponen Mattessich (2002) y (nos llega por) Cañibano (1988), él mismo es un proceso retórico. El momento de invención de los argumentos (o Inventio) estaría representado por los momentos que conocemos como el principio de dualidad y la medición y valoración de los hechos económicos: en estos momentos del método contable lo que tenemos es un proceso de abstracción en el cual escogemos (inventamos) las características 'importantes' de los hechos económicos con el fin de (re)presentarlos a un público. Por otro lado, la Dispositio estaría presente en el momento de definir las formas de representación pues son las que nos permiten definir qué tipo de información vamos a presentar y en qué orden; es este el momento en el que, hablando de estados financieros, definimos cómo representar los activos, los pasivos, los ingresos, etc. Por último, la Ecolutio, la presentación, estaría dada en el momento de agregación de la información contable, momento en el que la información deja de estar en manos de los contables (los científicos de la contabilidad) para ser pública, para ser manejada por otros, para tomar decisiones, etc.

Los Tipos de Argumentos no dejan de estar presentes en la contabilidad. Aquí es donde la contabilidad puede llegar a ser vista como una disciplina no neutral y llena de juicios de valor, pues tanto el Pathos como el Ethos, argumentos de los que se ha querido alejar la ciencia (y la contabilidad), son fundamentales en la elaboración de informes contables o de 
reportes científicos. Para hablar con ejemplos, veamos el caso de un informe de estados financieros. A simple vista estaríamos hablando de una especie de Logos, un conjunto de argumentos que no apelan a los sentimientos, ni las valoraciones, sino que se basan en hechos reales, comprobables, demostrables, etc.; hasta este punto, entonces, toda información contable representa un Logos. Sin embargo, en medio de este logos contable se apela constantemente a los sentimientos y a los juicios de valor, los que nos llevan a decir que el Pathos y el Ethos se encuentran en la contabilidad. Dentro del balance de Bavaria (Segundo Semestre de 2008) encontramos la siguiente expresión:

“...la utilidad bruta fue de \$1.279.491 millones, representando un incremento del $11,9 \%$ respecto al primer semestre del mismo año. El margen bruto fue de $66,2 \%$ en el segundo semestre del 2008, mayor en $0.3 \%$ con respecto al semestre anterior cuando representó el 65,9\%”. (Bavaria, 2008).

De entrada parecen sólo datos, sin ningún juicio de valor, sólo representaciones del desempeño de la organización durante un periodo de tiempo especial. Sin embargo, hacer énfasis en que la utilidad de este periodo incrementó o fue mayor que la utilidad del periodo anterior, habla muy bien de la organización, de su crecimiento, de su buen desempeño (Ethos) y al mismo tiempo apela a las expectativas de los inversores externos (actuales y/o potenciales) quienes al ver que la utilidad de la organización está creciendo, tendrán motivos para decidir invertir o mantener su inversión en la organización (Pathos). Ejemplos como estos los podemos encontrar en todos los informes contables e incluso en técnicas contables como las del análisis financiero.

Como ya se ha dicho, a pesar de querer mostrarse como alejada de la literatura y de las artes retóricas, gracias a su jerga especializada, es innegable la presencia de Figuras Retóricas en la ciencia. La contabilidad no está lejana de ello. Para hablar solamente de la Metáfora, la contabilidad usa en su lenguaje un conjunto infinito de metáforas para referirse a la realidad, a los hechos económicos. Baste con preguntarnos el significado de palabras como activo, pasivo o ingresos. Los tres términos son metáforas. Según el Diccionario de la Real Academia Española de la Lengua - RAE, estos significan (obviando el hecho de que los significados contables ya son aceptados en la RAE): "Que obra o tiene virtud de obrar"; "Se dice del sujeto que recibe la acción del agente, sin cooperar con ella"; y, "Acción de ingresar" (Ingresar: Entrar en un lugar). Mirando estos tres significados detenidamente podríamos decir que no hay cosa más activa que un pasivo, no hay cosa más pasiva que un activo y que los ingresos no son realmente ingresos. Para nosotros estas tres palabras no son literales, son metafóricas. Un activo lo es no porque tenga la capacidad de obrar, sino porque representa los bienes de la empresa, con los cuales ella cumple su objeto social; un pasivo lo es no por su falta de actividad, sino por la capacidad de acción que tiene un tercero sobre la organización; un ingreso no lo es porque entren los recursos a la empresa, sino porque se generan derechos para la organización en virtud de sus actividades cotidianas, que aumentarán los activos de la misma. Las demás figuras retóricas, según Lakoff \& Johnson (1986) son formas diversas de metáfora, por lo cual, con el presente ejemplo, es suficiente.

Para cerrar esta sección, consideremos el caso de las audiencias, las ausencias y las autoridades en el discurso contable. Mucho se ha hablado acerca de quienes son los usuarios de la información contable. Se ha llegado a plantear que todos los que estén interesados en una empresa son usuarios de su información contable. Sin embargo, la información contable está lejos de ser dirigida a cualquier usuario. Las audiencias a las que se dirige el discurso contable son pocas: en ejemplos como el que vimos de Bavaria se puede argumentar que la audiencia preferente son los inversores de capital, aquellos a quienes las utilidades de una empresa pueden ser importantes; un estado de costos, en el que se expresa el valor dedicado a la mano de obra, no está dirigido a la comunidad de trabajadores de la organización, se dirige a los administrativos y tomadores de decisiones quienes definirán los rumbos a seguir en su relación con los trabajadores actuales y potenciales.

Por otro lado, las ausencias se evidencian en el lenguaje ampliamente monetario de la contabilidad: el 
valor monetario de un bien es solamente una de las características que posee el bien mismo; ésta no nos habla acerca del estado en el que se encuentra, del nivel de intervención del hombre sobre él, o del valor cultural que posee para una comunidad específica; muchas críticas se han hecho a la contabilidad en relación con lo que deja de representar: el deterioro ambiental, el aporte o perjuicio social, etc., todos ellos ausencias en la contabilidad.

En última instancia, las autoridades usadas en contabilidad son de diferente tipo: una primera autoridad la encontramos en la firma que es impuesta por el contador, sobre los estados financieros, apoyada por su número de tarjeta profesional, o en otras palabras, el hecho de que el que (se dice que) elabora los estados financieros posea una tarjeta profesional es la muestra de que toda una profesión está apoyando la bondad de los estados financieros firmados por tal contador; una segunda autoridad se encuentra en la apelación constante a normas y principios de contabilidad que agregan valor a la información producida en cuanto ésta está elaborada de acuerdo a una tradición o a una legalidad; otra forma de autoridad en contabilidad es la revisión de los estados financieros por parte de un auditor o un revisor fiscal, los cuales dan fe de la veracidad de la información presentada al público.

Todos estos elementos vistos de manera superficial nos ayudan para mostrar (o para inventarnos el cuento de) que la contabilidad, al igual que la ciencia o que todo discurso producido en la sociedad, es altamente retórica.

\subsection{Potenciales de Investigación Retórica en Contabilidad}

La investigación retórica en contabilidad, lejos de ser una novedad, ha tenido un amplio desarrollo desde la década de los 80's del siglo pasado. En esta sección se explorará la retórica en contabilidad desde seis ámbitos especiales. Estos ámbitos expresan, a través de ejemplos, por un lado, los avances que la investigación retórica ha tenido en la investigación contable internacional $\mathrm{y}$, por otro, los potenciales de investigación que en nuestro país puede llegar a tener. El primer ámbito dará cuenta de la investigación que se ha centrado en analizar el uso de la retórica de la ciencia en la disciplina contable, tratando de mostrar así a la contabilidad como una disciplina científica. En el segundo, se explorarán algunas indagaciones acerca de la retórica que es utilizada en los procesos de normalización contable y en las normas de contabilidad. Un tercer ámbito explorado se relaciona con la retórica que es usada en diferentes teorías contables. En cuarto lugar, se presentan investigaciones que se han concentrado en la retórica usada en diferentes procesos de formación contable. Luego, se hace un recorrido por indagaciones que han sido realizadas en pro de un análisis de la retórica usada en la práctica contable, como, por ejemplo, en los informes anuales. El último ámbito explora miradas acerca de la contabilidad como un dispositivo discursivo o retórico utilizado por otras disciplinas o personas 'ajenas' a la disciplina contable.

\subsubsection{La retórica de la Contabilidad como Ciencia}

En primer lugar podremos dirigir nuestra mirada a las construcciones académicas que sobre la contabilidad se han hecho de manera que podamos analizar, a la luz de la retórica de la ciencia y de la investigación, el proceso de construcción de la contabilidad, como disciplina de conocimiento. Un ejercicio que han asumido trabajos como el de Mouck (1992) en su análisis de la retórica del texto de la Positive Accounting Theory de Watts y Zimmerman; el de Amernic (1997) con su revisión a la retórica de la investigación utilizada en un artículo científico; o el de Reiter \& Williams (1997), al evaluar la retórica científica utilizada en una conferencia sobre Economía Financiera.

El texto de Mouck (1992) inicia considerando el texto de Positive Accounting Theory como un relato, una narrativa literaria que puede ser analizada a través de la crítica retórica. Después de mostrar las principales tesis y argumentos del libro, Mouck analiza las características retóricas del mismo. Él considera que este libro ha sido tan 'exitoso' entre los investigadores contables en particular gracias a la retórica científica y a la retórica rebelde usadas por los autores. Con respecto a la retórica científica, Mouck enuncia los elementos presentes en el texto: interés por mostrar a los científicos o los teó- 
ricos como neutrales; asume como científica toda investigación de carácter empírico (descriptivo), dejando de lado los estudios normativos; utiliza un lenguaje naturalizador por el cual establece que la realidad se comporta de acuerdo con leyes inalterables; el uso de metáforas y alegorías, expresadas en particular en los 'modelos' usados por Watts y Zimmerman y en su presentación de las empresas como 'nexos de contratos'; apelaciones a la Economía (Neoclásica) como autoridad académica; entre otras. De la retórica de la rebelión se puede decir que el éxito de la teoría positiva empalma con el momento histórico en el que se consideraba cualquier intervención regulativa como un limitante del mercado y sus fuerzas 'naturales'; la teoría positiva niega la capacidad de la regulación contable para coordinar la presentación de informes contables.

Este tipo de investigación es útil para evaluar todo tipo de enunciaciones teóricas que sobre la contabilidad nos lleguen de otros contextos o se produzcan en el nuestro. No se trata de limitar o negar el carácter científico que puede tener la contabilidad, sino, por el contrario, reconocer que a pesar de ser un trabajo riguroso, 'científico', la academia contable no está lejos de ser una práctica productora de textos, narrativas, relatos, socialmente construidos y susceptibles de ser evaluados.

\subsubsection{Retórica de la Normatividad Contable y de los Procesos de Normalización}

Como se había enunciado, un segundo ámbito podría dirigir nuestra investigación hacia los procesos de formulación de normatividad contable, nacional o internacional, de modo que nos lleve a comprender la dinámica de dichos procesos y el papel de las estrategias retóricas en la estabilización de una u otra normatividad o normalizador. Análisis de este tipo se puede observar en el trabajo de Jupe (2000) que analiza la retórica auto-referencial usada por los actores negociantes en la definición de estándares contables con el fin de legitimar las prácticas contables de las grandes corporaciones; o de Young (2003), quien analizó la retórica del buen emisor de estándares, presente en los estándares de contabilidad del FASB de Estados Unidos.
Young (2003) argumenta que las estrategias retóricas empleadas por el FASB construyen la imagen de que un estándar contable específico es 'bueno', silenciando las alternativas y las posibles críticas y mostrando al FASB como un 'buen' emisor de estándares. Así, estas estrategias, ayudan a mostrar al estándar como un producto técnico, fortaleciendo el valor aceptado de la objetividad en la contabilidad y en los estándares que la regulan.

Reconocer el carácter retórico de la normatividad contable y de los emisores de estándares puede ayudar a la evaluación crítica de la normatividad existente, de la normatividad emergente y de los mismos emisores de normas. En particular, evaluaciones de este tipo son necesarias al momento de evaluar la posible adopción (adaptación, convergencia, etc.) de estándares internacionales de contabilidad.

\subsubsection{Retórica de las Teorías Contables}

Otro de los ámbitos que pueden ser abordados dentro de la investigación retórica son las Teorías Contables, o en otras palabras, todo aquel conjunto de ideas acerca de lo que se hace o puede hacerse con la contabilidad, su sistematización y argumentación como modelo a seguir. Es el caso de la Partida Doble, como una de las herramientas básicas de la contabilidad moderna; o el Balanced Scorecard, una contemporánea herramienta de gestión.

Dentro del primer caso, podemos encontrar el trabajo de Aho (1985) en el que argumenta que lejos de ser parte de la racionalidad capitalista, tal y como llegaron a considerar Weber y Sombart, la partida doble podría ser analizada como un ejercicio retórico para justificar la existencia del comercio en el medioevo tardío. Aho, apoyándose en el texto de Paciolo, De Computis et Scripturis, considera que el proceso de elaboración del Libro Mayor de un mercader es similar al proceso de construcción de un argumento. La Contabilidad por Partida Doble poseería los tres momentos básicos de la construcción de argumentos: Inventio, Dispositio y Elocutio. Para Aho, el origen de la partida doble está sumamente ligado a las prácticas religiosas como la confesión, a la enseñanza de la retórica en los círculos académicos, e incluso a las consideraciones estéticas del renacimiento. 
En el mismo orden, por otra parte, Carruthers \& Espeland (1991) muestran que la naturaleza balanceada de la partida doble documenta la naturaleza balanceada de las firmas, lo que le otorga una legitimidad y equidad a los negocios. En el mismo tema, Thompson (1994) muestra que la partida doble crea una apariencia de control sobre los flujos de bienes y servicios al establecer una medida de ellos.

El trabajo de Norreklit (2003) se centra en el análisis retórico de uno de los trabajos más influyentes en la contabilidad de gestión actual: The Balanced Scorecard (TBSC) de Kaplan y Norton. El texto, según Norreklit, adquiere fuerza con solo mirar las condiciones en las que aparece: TBSC es un texto producto de dos altos ejecutivos de la consultoría de gestión y de la Escuela de Negocios de la Universidad de Harvard. Por otro lado, al sumegirse en el texto del primer capítulo, Norreklit muestra que es un texto más emotivo que racional: apela a la obsolescencia del modelo contable y a la necesidad de un nuevo modelo, con el fin de ser competitivos en la "nueva era de la información", que supera la "era industrial" en la que surgió el antiguo modelo. Norreklit evalúa el texto del TBSC como un texto poco científico, confuso y emocional, en el que hay un uso excesivo de metáforas, analogías, con un estilo irónico, antitético, e inmerso en lo que él llama el "género de los Gurús del Management". Si bien el texto de Norreklit muestra el carácter retórico de TBSC, posee una versión parcializada del mismo al no considerarlo científico debido al lenguaje utilizado por los autores. Más allá hay una defensa de los paradigmas racionales de la ciencia moderna.

Estos ejemplos nos dan luces acerca de la posibilidad de evaluar el carácter retórico de los diferentes enunciados teóricos que han sido desarrollados acerca de la contabilidad. Enunciados que pueden encontrarse en todos los espacios de la contabilidad: contabilidad financiera, contabilidad de gestión y de costos, auditoría, finanzas, etc.

\subsubsection{Retórica en la Educación Contable}

El cuarto ámbito que podemos tener en cuenta en la investigación retórica se relaciona con las prácticas de educación contable, ya sean éstas de carácter formal o informal. Análisis de este tipo incluyen los trabajos de Amernic \& Craig (2000b) que identifican las estrategias retóricas de la Guía para Entender las Finanzas de la IBM; o el trabajo de McGoun, Bettner $\&$ Coyne (2007) que se relaciona con algunas de las metáforas utilizadas en la educación contable.

El texto de Amernic \& Craig (2000b) inicia con la evaluación a la preocupación que algunos académicos tienen acerca de la posibilidad de que las grandes corporaciones lleguen a invadir el sector educativo y la imposibilidad que tienen las instituciones de educación de competir con aquellas. Para los autores, además de que ésta sea una posibilidad real, las corporaciones ya se encuentran formando contadores, y igratis!, a través de mecanismos no tradicionales, como las páginas web. Así, toman el caso de la Guía Para Entender las Finanzas disponible en la página web de la IBM (en el año 1998). Esta guía, según los autores, enseña la contabilidad financiera de un modo no-problemático, es decir, dejando de lado las profundas controversias que alrededor de la elaboración de informes contables existen en los medios académicos y regulativos. Por otro lado, muestran las diferentes metáforas presentes en la Guía, tales como:

- Metáforas verbales: 'Una compañía es una entidad limitada (con fronteras)'; 'el efectivo es la sangre de los negocios'; 'una empresa es una persona/ un organismo biológico'; 'los estados financieros son un lenguaje'; 'los estados financieros son contenedores'; o 'los estados financieros son fotografías'; o,

- Metáforas visuales: 'IBM es un guía'; o 'una compañía es un equipo deportivo'. Amernic \& Craig (2000b) concluyen que IBM enseña contabilidad, pero un tipo de contabilidad que ignora las dimensiones sociales y desproblematiza las numerosas decisiones y estructuras sociales presentes en las metáforas enseñadas en la Guía.

Las investigaciones centradas en la retórica de la educación contable pueden llevarnos a evaluar los (pre)juicios bajo los cuales los contadores 'del futuro' son formados y la manera en que ellos pueden llegar a observar y a actuar en el mundo laboral. Estas investigaciones pueden llevarse a cabo en el aula de clase, en los textos guía, en los instrumentos de en- 
señanza virtual, e incluso, en los reportes contables de las empresas, dado que estos últimos pueden ser unas importantes herramientas pedagógicas.

\subsubsection{Retórica dentro de la Práctica Contable}

Un quinto tipo de investigación puede ser llevado a cabo en el marco de las prácticas organizacionales, identificando el papel de la retórica contable en la consolidación de un tipo de organización específico. La retórica puede ser encontrada en momentos como la elección de una práctica contable particular, en los procesos de elaboración de informes contables o en los informes contables entregados al exterior de la organización. Trabajos en esta materia los han realizado investigadores como Hooper \& Pratt (1995) quienes analizaron el papel de la contabilidad y su retórica en la New Zealand Native Land Company; Courtis (2004), quien observó las prácticas de producción de informes anuales tomando en cuenta principalmente el papel del color en dichos informes; Bourguignon (2005) quien llevó a cabo un análisis crítico acerca del proceso de reificación de la creación de valor empresarial; Crowther, Carter \& Cooper (2006) que a la luz de la poética analizaron los informes anuales de diversas compañías de prestación de servicio de acueducto; o Amernic \& Craig (2000a) quienes evaluaron el papel de la contabilidad en la primera carta a los accionistas emitida por Walt Disney en 1940.

\subsubsection{Retórica de lo contable en otros campos}

Otra posible esfera puede ser la llevada a cabo por investigadores 'externos' a la disciplina, como Aho (1985); Carruthers \& Espeland (1991); Klamer y McCloskey (1992) o Porter (1992), quienes han indagado en el papel que la contabilidad y su retórica juegan en las relaciones sociales en general y en el desempeño de otras disciplinas en particular (Christensen, 2004; Mellemvik, 1997; Moerman \& van der Laan, 2007; Solli \& Jönsson, 1997).

La aparente objetividad y neutralidad de la contabilidad sirve como argumento de autoridad, como metáfora, para otras disciplinas. Klamer \& McCloskey (1992) muestran cómo la economía se alimenta de los conceptos contables para llevar a cabo sus mode- los y sus argumentaciones. "La economía (...) está dominada por ideas contables. Muchos economistas podrían ser sorprendidos por esta proposición, pero en efecto su campo es reglamentado por poco. Costo y beneficio, racionalidad y cálculo, dependen de un conjunto de libros como un sistema cerrado, cubriendo por definición cualquier cosa que haya que cubrir. Los inventarios y los flujos, el capital y el ingreso; el producto neto de la depreciación; las erogaciones se igualan a los costos; el flujo circular; la escasez; la elección bajo constreñimientos" (Klamer \& McCloskey, 1992, 146).

\section{Conclusiones}

Cuatro aspectos se han tocado en este artículo. En primer lugar, el carácter construido de la ciencia y las visiones que de ella han dado la filosofía, la historia y la sociología de la ciencia de manera tradicional y las alternativas que surgen a partir del surgimiento de los estudios sociales de la ciencia. En segundo lugar, el papel que juega la retórica en la construcción del conocimiento (científico) y las posibilidades y categorías que aportan los estudios en retórica para el estudio de la ciencia, la contabilidad y en general todo discurso propuesto en la sociedad. Tercero, las visiones que se han dado sobre la ciencia han tenido expresiones importantes en las miradas que sobre la contabilidad se hacen; así, estas miradas son abordadas para mostrar cómo la contabilidad ha sido una disciplina de conocimiento construida a través de las prácticas y teorías que a diario emergen. Por último, se abordó el carácter retórico que la contabilidad, como discurso emitido socialmente, posee y algunas de las dimensiones en las cuales este carácter puede ser analizado.

Las visiones acerca de la ciencia y su naturaleza fueron abordadas desde diversos espectros. Se reconocen así, perspectivas que parten desde una mirada esencialista de la ciencia; desde estas perspectivas, el conocimiento científico se considera como el único conocimiento verdadero. Por otro lado, el conocimiento científico es reconocido como producido sin la intervención de factores 'externos': políticos, sociales, económicos, sentimentales, etc.; por el contrario, es producido gracias a la correcta aplicación del 'método científico' y su coherencia lógica con el conocimiento ya validado. Sin embargo, es de reco- 
nocer que el esencialismo entra también en aquellas perspectivas que consideran el conocimiento científico como producto enteramente social; así, estas perspectivas asumen el análisis del conocimiento científico como producto de condiciones sociales, políticas, económicas, sentimentales, etc., sin atender a su estructura interna.

Un último grupo de perspectivas, reunidas, particularmente, en los llamados Estudios Sociales de la Ciencia y la Tecnología, consideran que no es debido separar entre factores externos e internos de la ciencia, así como entre: sujeto y objeto, o entre contexto de descubrimiento y contexto de justificación. Para los investigadores que asumen estas perspectivas, los principios que hay que asumir para analizar la ciencia y la tecnología son: simetría, imparcialidad, causalidad y reflexividad. A partir de estos principios se ve a la ciencia como producto de una red indeterminada de factores humanos, naturales y artificiales que permiten que un tipo de conocimiento sea aceptado por la comunidad científica y tenga implicancias para la sociedad en su conjunto; es producto de relaciones de poder y al mismo tiempo legitima diversas formas de ordenamiento social; es producto de múltiples intereses que confluyen y entran en conflicto con el fin de definir el conocimiento válido. Así, algunas de las perspectivas que se abordaron incluyen: el Programa Fuerte de la Sociología del Conocimiento, el Social-Costructivismo, los Estudios Etnográficos, los Estudios de Laboratorio, los Estudios Discursivos y la Teoría del Actor-Red.

Dentro de estas perspectivas se hace especial énfasis en los estudios retóricos de la ciencia. Se considera a la retórica como el uso del discurso para persuadir a un auditorio y conducirlo hacia un fin particular. Estos estudios consideran a la ciencia como poseedora de una retórica particular, contrario a las visiones tradicionales que hablan de la ciencia como no retórica, sino objetiva y neutral. Dentro de esta retórica se incluyen: estilo impersonal, estructura de sus discursos (problema, marco teórico, metodología, resultados, conclusiones, para hablar de la estructura general de los artículos científicos), apelación a autoridades (teorías, citaciones, autores básicos, etc.), continuo uso de metáforas (no solo en sus expresiones verbales sino en sus modelos o inscripciones tal como McCloskey y Latour lo sugieren), uso de jergas específicas propias de cada disciplina, construcción de 'relatos' acerca del proceso de construcción del conocimiento particular, entre otros elementos que normalmente han sido analizados dentro de la crítica literaria o del discurso político.

En un afán por alcanzar el reconocimiento de ciencia para la contabilidad, los teóricos de la contabilidad han apelado a los argumentos esencialistas mostrando a la contabilidad como una ciencia objetiva, neutral, con teorías lógicas, método particular y objeto de conocimiento. Estos argumentos parten de la consideración de la realidad como externa al sujeto contable, y a la contabilidad como reflejo fiel de dicha realidad. Por otro lado han emergido miradas que asumen una visión constructivista de la contabilidad, viéndola como un tipo de conocimiento producto de múltiples factores, humanos y no humanos, que hacen de ella un conocimiento válido y que al mismo tiempo ayuda a construir un tipo particular de sociedad a través de los diferentes ordenamientos y relaciones de poder que ella legitima. Estas visiones adquieren sus bases, principalmente, de los argumentos construidos por los Estudios Sociales de la Ciencia y la Tecnología. De allí, el estudio se ha centrado en el papel que poseen diversos actores, instituciones, discursos, tecnologías duras y blandas, condiciones económicas, sociales y políticas, etc., en la construcción de un tipo particular de conocimiento contable para un tipo particular de sociedad.

De estas perspectivas se ha hecho especial énfasis en los estudios retóricos que sobre la contabilidad se han realizado y se pueden llevar a cabo en nuestro contexto específico. La contabilidad posee una retórica particular que incluye: un estilo propio, estructura dentro de sus productos (analizando en particular la producción de informes contables), el uso de metáforas, la apelación a autoridades, entre otros; y que puede ser vista en diferentes dimensiones: las teorías contables, el proceso de educación contable, las normas y los procesos de normalización, el uso que se hace del discurso contable por otras disciplinas o la retórica de la investigación contable.

Por otro lado, es necesario reafirmar que cuando se habla de que la contabilidad posee una retórica 
particular, en ningún momento se afirma que lo que la contabilidad expresa es falso. Todo producto de la contabilidad, como todo producto de la ciencia, al ser discursos construidos con un fin, hace uso de dispositivos retóricos especiales, para presentar una verdad particular a un público específico que la acepta y la legitima. Por supuesto, no se ignora la capacidad de manipulación que se puede llevar a cabo para presentar cierto tipo de información como información verdadera.

\section{Referencias}

Aho, J. A. (1985) Rhetoric and the Invention of Double Entry Bookkeeping. En: Rhetorica: A Journal of the History of Rhetoric, 3, 21-43.

Álvarez, H. (2007) Contabilidad, Valoración y Distribución de la Riqueza: Una Visión Crítica. En: Lúmina, 172-204.

Amernic, J. H. (1997) Two Readings and an Epilogue: A Commentary on the Voice of Seduction in Mynatt et. al. Critical Perspectives on Accounting, 8, 693-716.

Amernic, J. H. \& Craig, R. J. (2000a) Accountability and Rhetoric During a Crisis: Walt Disney's 1940 Letter to Stockholders. En: Accounting Historians Journal, 27, 49-86.

Amernic, J. H. \& Craig, R. J. (2000b) The Rhetoric of Teaching Financial Accounting on the Corporate Web: A Critical Review of Content and Metaphor in IBM's Internet Webpage Guide to Undestanding Financials. Critical Perspectives on Accounting, $11,259-287$

Araujo, J. A. (2007) Los recursos: objeto de estudio de la Contabilidad. Contaduría, Universidad de Antioquia, 177-186.

Arévalo, N. E. \& Quinche, F. L. (2008) Importancia del Estudio de Caso en Contabilidad. In Centro Colombiano de Investigación Contable C-CINCO (Ed.), VII Simposio Nacional de Investigación Contable y Docencia (p 29-40)

Ariza, E. D. (1996) Una Aproximación a la Naturaleza de la Contabilidad. En: Lúmina, 4-16.

Ashmore, M., Myers, G., \& Potter, J. (1994) Seven Days in the Library: Discourse, Rhetoric, Reflexivity. In S.Jasanoff, G. Markle, J. Petersen, \& T. Pinch (Eds.), Handbook of Science, Technology and Society (p 321-342) London: Sage.

Bavaria, S. A. (2008) Informe a la Asamblea General Ordinaria, Segundo Semestre de 2008.

Bazerman, C. (1988) Shaping Written Knowlegde. The Genre and Activity of the Experimental Article in Science. Madison: The University of Wisconsin Press.

Bazerman, C., Little, J., Bettel, L., Chavkin, T., Fouquette, D., \& Garufis, J. (2005) Reference Guide to Writing Across the Curriculum. Indiana: Parlor Press.

Belkaoui, A. (1985) Accounting Theory. San Diego: Harcourt Brace Jovanovich.

Bijker, W. (1994) The Social Construction of Flourescent Light, or How an Artifact was Invented in its Diffusion Stage. In Shaping Technology/Building Society (p 75-104) London: MIT Press.

Bijker, W. (1997) La Construcción Social de la Baquelita: Hacia una Teoría de la Innovación. In M.González, J. López, \& J. Luján
(Eds.), Ciencia, Tecnología y Sociedad. Lecturas Seleccionadas (p 103-130) Barcelona: Ariel.

Bloor, D. (1998) Conocimiento e Imaginario Social. Barcelona: Gedisa.

Bourguignon, A. (2005) Management Accounting and Value Creation: The Profit and Loss Reification. En: Critical Perspectives on Accounting, 16, 353-389.

Briers, M. \& Chua, W. F. (2001) The Role of Actor-Networks and Boundary Objects in Management Accounting Change: A Field Study of an Implementation of Activity-Based Costing. En: Accounting, Organizations and Society, 26, 237-269.

Callon, M. (1980) Struggles and Negotiations to Define What is Problematic and What is not. The Socio-logic of Translation. In K. Knorr-Cetina (Ed.), The Social Process of Scientific Investigation (p 197-219) London: D. Reidel Publishing Company.

Callon, M. (1986) Some Elements of a Sociology of Translation: Domestication of the Scallops and the Fishermen of St. Brieuc Bay. In J.Law (Ed.), Power, Action and Belief. A New Sociology of Knowledge? (p 196-233) London: Routledge.

Callon, M. (1989) Society in the Making: the Study of Technology as a Tool for Sociological Analysis. In W.Bijker, T. Hughes, \& T. Pinch (Eds.), The Social Construction of Technological Systems (p 83-105) London: MIT Press.

Cañibano, L. (1988) Contabilidad: Análisis Contable de la Realidad Económica. Madrid: Editorial Piramide.

Cañibano, L. (1996) Los Programas de Investigación en Contabilidad. Contaduría, Universidad de Antioquia, 13-61.

Carruthers, B. G. \& Espeland, W. N. (1991) Accounting for Rationality: Double-Entry Bookkeeping and the Rhetoric of Economic Rationality. En: The American Journal of Sociology, 97, 31-69.

Chalmers, A. (1999) ¿Qué es esa Cosa Llamada Ciencia? Madrid: Siglo XXI Editores.

Christensen, M. (2004) Accounting by Words not Numbers: The Handmaiden of Power in the Academy. En: Critical Perspectives on Accounting, 15, 485-512.

Chua, W. F. (1986) Radical Developments in Accounting Thought. En: The Accounting Review, 61, 601-632.

Chua, W. F. \& Preston, A. (1994) Worrying about Accounting Health Care. En: Accounting, Auditing and Accountability Journal, 7.

Clower, R. (1988) The Ideas of Economists. In A.Klamer, D. McCloskey, \& R. Solow (Eds.), The Consequences of Economic Rhetoric ( Cambridge: Cambridge University Press.

Collins, H. (1997) Un Programa Empírico del Relativismo en Sociología del Conocimiento. In M.González, J. López, \& J. Luján (Eds.), Ciencia, Tecnología y Sociedad. Lecturas Seleccionadas (p 49-70) Barcelona: Ariel.

Courtis, J. K. (2004) Colour as Visual Rhetoric in Financial Reporting. En: Accounting Forum, 28, 265-281.

Crowther, D., Carter, C., \& Cooper, S. (2006) The Poetics of Corporate Reporting: Evidence from the UK Water Industry. En: Critical Perspectives on Accounting, 17, 175-201.

Dechow, N. \& Mouritsen, J. (2005) Enterprise Resource Planning Systems, Management Control and the Quest for Integration. En: Accounting, Organizations and Society, 30, 691-733.

García, C. L. (2001) Elementos para una Teoría General de la Contabilidad. Buenos Aires: La Ley.

García, M. (1998) Últimas Tendencias de la Metodología de la Contabilidad. En: Lúmina, 5-9.

Gilbert, G. N. \& Mulkay, M. (1994) El Discurso de los Científicos como Tema. In J.M.Iranzo, R. Blanco, T. González, C. Torres, 
\& A. Cotillo (Eds.), Sociología de la Ciencia y la Tecnología (p 205-220) Madrid: CSIC.

Gill, A. \& Whedbee, K. (2000) Retórica. In T.van Dijk (Ed.), El Discurso como Estructura y Proceso. Estudios del Discurso: Introducción Multidisciplinaria (p 233-270) Barcelona: Gedisa.

Giraldo, G. (2008) Repercusiones de la Teoría Crítica en la Investigación Contable. In VII Simposio Nacional de Investigación Contable y Docencia (p 77-94)

Gómez, M. (2004) Breve Introducción al Estado del Arte de la Orientación Crítica en la Disciplina Contable. Contaduría, Universidad de Antioquia, 113-132.

Gross, A. (2006) Starring the Text: The Place of Rhetoric in Science Studies. Illinois: Southern Illinois University Press.

Hooper, K. \& Pratt, M. (1995) Discourse and Rhetoric. The Case of the New Zealand Native Land Company. En: Accounting, Auditing and Accountability Journal, 8, 10-37.

Hopper, T. \& Powell, A. (1985) Making Sense of Research into the Organizational and Social Aspects of Management Accounting: A Review of Its Underlying Assumptions. En: Journal of Management Studies, 429-465.

Hopwood, A. \& Miller, P. (1994) Accounting as Social and Institutional Practice. Cambridge: Cambridge University Press.

Hoskin, K. \& Macve, R. (1994) Writing, Examining, Disciplining: The Genesis of Accounting's Modern Power. In A. Hopwood \& Miller (Eds.), Accounting as Social and Institutional Practice ( Cambridge: Cambridge University Press.

Jupe, R. E. (2000) Self-Referential Lobbyng of the Accounting Standards Board: The Case of Financial Reporting Standard No. 1. En: Critical Perspectives on Accounting, 11, 337-359.

Justesen, L. \& Mouritsen, J. (2009) The Triple Visual: Translations Between Photographs, 3-D Visualizations and Calculations. En: Accounting, Auditing and Accountability Journal, 22, 973-990.

Klamer, A. \& McCloskey, D. (1992) Accounting as the Master Metaphor of Economics. En: The European Accounting Review, 1. 145-160.

Knorr-Cetina, K. (1994) Los Estudios Etnográficos del Trabajo Científico: Hacia una Interpretación Constructivista de la Ciencia. In J.M.Iranzo, R. Blanco, T. González, C. Torres, \& A. Cotillo (Eds.), Sociología de la Ciencia y la Tecnología ( $p$ 187-204) Madrid: CSIC

Knorr-Cetina, K. (2005) La Fabricación del Conocimiento. Un Ensayo sobre el Carácter Constructivista y Contextual de la Ciencia. Buenos Aires: Universidad Nacional de Quilmes Editorial.

Kuhn, T. (2007) La Estructura de las Revoluciones Científicas. México: Fondo de Cultura Económica.

Lakatos, I. (1987) La Historia de la Ciencia y sus Reconstrucciones Racionales. Madrid: Tecnos.

Lakatos, I. (1989) La Metodología de los Programas de Investigación. Madrid: Alianza.

Lakoff, G. \& Johnson, M. (1986) Metáforas de la vida cotidiana. Madrid: Cátedra.

Lara, J. A. (1991) Teoría contable y estructuras paradigmáticas. Contaduría, Universidad de Antioquia, 231-250.

Larrinaga, C. (1999) Perspectivas Alternativas de Investigación en Contabilidad: Una Revisión. Revista de Contabilidad, 2, 103-131.

Latour, B. (1991) Technology is Society Made Durable. In J.Law (Ed.), A Sociology of Monsters: Essays on Power, Technology and Domination (p 103-131) London: Routledge.

Latour, B. (1992) Ciencia en Acción. Cómo Seguir a los Científicos e Ingenieros. Barcelona: Editorial Labor.
Latour, B. (1994) Where are the Missing Masses? The Sociology of a Few Mundane Artifacts. In W.Bijker \& J. Law (Eds.), Shaping Technology/Building Society ( London: MIT Press.

Latour, B. (2001) La Esperanza de Pandora. Ensayos sobre la Realidad de los Estudios de la Ciencia. Barcelona: Gedisa.

Latour, B. (2008) Reensamblar lo Social. Una Introduccion a la Teoría del Actor-Red. Buenos Aires: Manantial.

Latour, B. \& Woolgar, S. (1995) La Vida en el Laboratorio. La Construcción de los Hechos Científicos. Madrid: Alianza.

Law, J. (1986) On the Methods of Long-Distance Control: Vessels, Navigation and the Portugesse Route to India. In J.Law (Ed.), Power, Action and Belief. A New Sociology of Knowledge? ( $p$ 196-233) London: Routledge.

Law, J. \& Akrich, M. (1994) On Costumers and Costs: A Story from Public Sector Science. In M.Power (Ed.), Accounting and Science. Natural Inquiry and Commercial Reason (p 120-150) London: Cambridge University Press.

Law, J. \& Callon, M. (1994) The Life and Death of an Aircraft: A Network Analysis of Technical Change. In W.Bijker \& J. Law (Eds.), Shaping Technology/Building Society (p 21-52) London: MIT Press.

Lemos de la Cruz, J. E. (2006) Filosofía de la ciencia y contabilidad: relación necesaria. Contaduría, Universidad de Antioquia, 57-70.

Lowe, A. (2000) The Construction of a Network at Health Waikato: The 'Towards Clinical Budgeting' Project. En: Accounting, Auditing and Accountability Journal, 13, 84-114.

Lowe, A. (2001a) Accounting Information Systems as KnowledgeObjetcs: Some Effects of Objectualization. En: Management Accounting Research, 12, 75-100.

Lowe, A. (2001b) After ANT - An Ilustrative Discussion of the Implications for Qualitative Accounting Case Research. En: Accounting, Auditing and Accountability Journal, 14, 327-351.

Lowe, A. (2004a) Methodology Choices and the Construction of Facts: Some Implications from Sociology of Scientific Knowledge. En: Critical Perspectives on Accounting, 15, 207-231.

Lowe, A. (2004b) Post-social Relations: Toward a Performative View of Accounting Knowledge. En: Accounting, Auditing and Accountability Journal, 17, 604-628.

Lowe, A. \& Koh, B. (2007) Inscribing the Organization: Representations in Dispute between Accounting and Production. En: Critical Perspectives on Accounting, 18, 952-974.

Lynch, M. (1990) The Externalized Retina: Selection and Methematization in the Visual Documentation of Objects in the Life Sciences. In M.Lynch \& S. Woolgar (Eds.), Representation in Scientific Practice (p 153-186) Cambridge: MIT Press.

Lynch, M., Livingstone, E., \& Garfinkel, H. (1994) El Orden Temporal en el Trabajo de Laboratorio. In J.M.Iranzo, R. Blanco, T. González, C. Torres, \& A. Cotillo (Eds.), Sociología de la Ciencia y la Tecnología (p 163-186) Madrid: CSIC.

Machado, M. A. (1994) Un nuevo concepto de contabilidad para el avance científico. Contaduría, Universidad de Antioquia, 113-125.

Machado, M. A. (1999) El complejo objeto de estudio de la contabilidad: por la vía constructiva. Contaduría, Universidad de Antioquia, 17-45.

Mardones, J. M. (2001) Filosofía de las Ciencias Humanas y Sociales. Barcelona: Anthropos.

Martínez, G. L. (2006) Los Paradigmas Contables: La Borrosa Impronta de una Interpretación Epistemológica. Contaduría, Universidad de Antioquia, 117-154. 
Mattessich, R. (1995) Critique of Accounting. Examination of the Foundations and Normative Structure of an Applied Discipline. Wesport: Quorum Books.

Mattessich, R. (2002) Contabilidad y Métodos Analíticos. Medición y Proyección del Ingreso y la Riqueza en la Microeconomía y en la Macroeconomía. Buenos Aires: La Ley.

McCloskey, D. (1983) The Rhetoric of Economics. En: Journal of Economic Literature, XXI, 481-517.

McCloskey, D. (1990) La Retórica de la Economía. Madrid: Alianza.

McCloskey, D. (1993) Si Eres tan Listo. La Narrativa de los Expertos en Economía. Madrid: Alianza.

McCloskey, D. (1994) How to Do a Rhetorical Analysis, and Why. In R.Backhouse (Ed.), Economic Methodology (p 319-342) London: Routledge.

McGoun, E. G., Bettner, M. S., \& Coyne, M. (2007) Pedagogic Metaphors and the Nature of Accounting Signification. En: Critical Perspectives on Accounting, 18, 213-230.

Mellemvik, F. (1997) Accounting, the Hidden Collage? Accounting in the Dialogues Between a City and its Financial Institutions. En: Scandinavian Journal of Management, 13, 191-207.

Merton, R. (1977) La Sociología de la Ciencia: Investigaciones Teóricas y Empíricas. Madrid: Alianza.

Miller, \& O'leary, T. (1987) Accounting and the Construction of Governable Person. Accounting, Organizations and Society, 12, 235-265.

Miller, \& O'leary, T. (1994) The Factory as Laboratory. In M.Power (Ed.), Accounting and Science. Natural Inquiry and Commercial Reason ( London: Cambridge University Press.

Miller, \& Rose, N. (2008) Governing the Present. Administerin Economic, Social and Personal Life. Cambridge: Polity Press.

Moerman, L. \& van der Laan, S. (2007) Pursuing Shareholder Value: The Rhetoric of James Hardie. En: Accounting Forum, 31, 354-369.

Montesinos, V. (1999) Formación y contrastación de las teorías científicas en contabilidad. En: Lúmina, 7-14.

Mouck, T. (1992) The Rhetoric of Science and the Rhetoric of Revolt in the 'Story' of Positive Accounting Theory. En: Accounting, Auditing and Accountability Journal, 5, 35-56.

Mouritsen, J., Hansen, A., \& Hansen, C. Ø. (2009) Short and Long Translations: Management Accounting Calculations and Innovation Management. En: Accounting, Organizations and Society, 34, 738-754.

Mouritsen, J. \& Larsen, H. T. (2005) The 2nd Wave of Knowledge Management: The Management Control of Knowledge Resources through Intellectual Capital Information. En: Management Accounting Research, 16, 371-394.

Mouritsen, J., Larsen, H. T., \& Bukh, N. (2001b) Valuing the Future: Intellectual Capital Suplements at Skandia. En: Accounting, Auditing and Accountability Journal, 14.

Mouritsen, J., Larsen, H. T., \& Hansen, A. (2002) 'Be Critical!' Critique and Naivete - Californian and French Connections in Critical Scandinavian Accounting Research. En: Critical Perspectives on Accounting, 13, 497-513.

Mouritsen, J. \& Thrane, S. (2006) Accounting, Network Complementarities and the Development of Inter-Organisational Relations. En: Accounting, Organizations and Society, 31, 241-275.

Nelson, J. S., Megill, A., \& McCloskey, D. (1987a) Rhetoric of Inquiry. In J.S.Nelson, A. Megill, \& D. McCloskey (Eds.), The Rhetoric of the Human Sciences. Language and Argument in Scholarship and Public Affairs (p3-18) Madison: The University or Wisconsin Press.

Nelson, J. S., Megill, A., \& McCloskey, D. (1987b) The Rhetoric of the Human Sciences. Language and Argument in Scholarship and Public Affairs. Madison: The University of Wisconsin Press.
Norreklit, H. (2003) The Balanced Scorecard: What is the Score? A Rhetorical Analysis of the Balanced Scorecard. En: Accounting, Organizations and Society, 28, 591-619.

Pinch, T. \& Bijker, W. (1989) The Social Construction of Facts and Artifacts or How the Sociology of Science and the Sociology of Technology Might Benefit Each Other. In W.Bijker, T. Hughes, \& T. Pinch (Eds.), The Social Construction of Technological Systems (p 17-50) London: MIT Press.

Porter, T. (1992) Quantification and the Accounting Ideal of Science. Social Studies of Science, 22, 633-651.

Potter, J. (1998) La Representación de la Realidad. Discurso, Retórica y Construcción Social. Barcelona: Paidós.

Power, M. (1994a) Accounting and Science. Natural Inquiry and Commercial Reason. Cambridge: Cambridge University Press.

Power, M. (1994b) The Audit Society. In A.Hopwood \& Miller (Eds.), Accounting as Social and Institutional Practice (p 299-316) Cambridge: Cambridge University Press.

Power, M. (1995) Auditing, Expertise and the Sociology of Technique. En: Critical Perspectives on Accounting, 6, 317-339.

Quinche, F. L. (2006) Historia de la Contabilidad: Una Revisión de las Perspectivas Tradicionalles y Críticas de Historiografía Contable. En: Revista Facultad de Ciencias Económicas: Investigación y Reflexión, XIV, 187-202.

Quinche, F. L. (2008) Una Evaluación Crítica de la Contabilidad Ambiental Empresarial. Revista Facultad de Ciencias Económicas: Investigación y Reflexión, XVI, 197-216.

Reiter, S. A. \& Williams, F. (1997) Scientific Conversation in Financial Economics. In V Interdisciplinary Perspectives on Accounting Conference.

Requena, J. M. (1977) La Homogenización de las Magnitudes en la Ciencia de la Contabilidad. Madrid: Ediciones ICE.

Restrepo, O. (2004) Retórica de la ciencia sin 'retórica'. Sobre autores, comunidades y contextos. En: Revista Colombiana de Sociología, 251-268.

Rueda, G. (2007) La Investigación Contable: Vínculos Ontológicos y las Posibilidades de la Investigación Interpretativa. Contaduría, Universidad de Antioquia, 119-132.

Ryan, B., Scapens, R., \& Theobald, M. (2004) Metodología de la Investigación en Contabilidad y Finanzas. Barcelona: Deusto.

Solli, R. \& Jönsson, S. (1997) Housekeeping? Yes, But Which House? Meaning and Accounting Context-ACase Study. En: Scandinavian Journal of Management, 13, 19-38.

Tascón, M. T. (1995) La contabilidad como disciplina científica. Contaduría, Universidad de Antioquia, 65-111.

Thompson, G. (1994) Early Double-Entry Bookkeeping and the Rhetoric of Accounting Calculation. In A.Hopwood \& Miller (Eds.), Accounting as Social and Institutional Practice (p 40-66) Cambridge: Cambridge University Press.

Tua, J. (1990) Algunas implicaciones del paradigma de utilidad en la disciplina contable. Contaduría, Universidad de Antioquia, 17-48.

Tua, J. (1995) Lecturas en Teoría e Investigación Contable. Medellín: CIJUF.

Woolgar, S. (1991) Ciencia: Abriendo la Caja Negra. (1 ed.) BarceIona: Anthropos.

Woolgar, S. (1994) Los estudios de laboratorio: un comentario sobre el estado de la cuestión. In J.M.Iranzo, R. Blanco, T. González, C. Torres, \&A. Cotillo (Eds.), Sociología de la Ciencia y la Tecnología (p 221-233) Madrid: CSIC

Young, J. J. (2003) Constructing, Persuading and Silencing: The Rhetoric of Accounting Standards. En: Accounting, Organizations and Society, 28, 621-638. 